\title{
Research
}

\section{How frequently do young people with potential cancer symptoms present in primary care?}

\begin{abstract}
Background

Although uncommon in teenagers and young adults, cancer is the leading cause of nonaccidental death in those aged $15-24$ years. $A$ prolonged period to cancer diagnosis in this cohort is reported and thought to be a consequence of the rarity of cancer in this age group, together with the complexity of presenting symptoms. Although diagnostic delay is perceived to be a problem for teenagers and young adults with cancer, little research has focused on their use of primary care services.
\end{abstract}

\section{Aim}

To determine how often teenagers and young adults consult, their reasons for doing so, and how often potential oncological symptoms ('alert' symptoms) appear.

\section{Design and setting}

Retrospective audit of consultations over 1 year Three general medical practices in Scotland.

\section{Method}

Medical records were examined for 2326 teenagers and young adults. Date of birth, sex and free-text relating to the consultation were recorded and coded according to an agreed coding system; symptoms of potential oncological significance were coded as alert symptoms.

\section{Results}

A total of 1659 teenagers and young adults (71.3\% of registered patients) attended their GP at least once. Females attended more frequently than males $(P<0.001)$, and older females more frequently than younger females $(P<0.001)$. Males exhibited no association between consultation frequency and age. The main reasons for consultation were pregnancy/contraception (15.8\%) and infection (15.7\%). Alert symptoms were uncommon, (reported in $4.0 \%$ of all consultations; 276 alert symptoms in 179 patients), and were not associated with age or sex. The most common alert symptoms were unexplained pain $(34.8 \%)$, unexplained fatigue $(14.5 \%)$, and lumps $(13.4 \%$. Two benign tumours were detected.

\section{Conclusion}

A high proportion of teenagers and young adults consult their GP. Alert symptoms are uncommon and generally occur in isolation. More research is required to confirm these findings in a larger cohort and to examine how GPs respond to such alert symptoms.

\section{Keywords}

cancer; diagnosis; primary health care; teenagers and young adults.

\section{INTRODUCTION}

Reducing the time to diagnosis for patients with cancer has become a priority for national health policy in the UK. ${ }^{1-4}$ Poorer survival rates, particularly 1-year survival, compared with other European countries are partly explained by more advanced disease at presentation and may also be due to a longer time to diagnosis for patients in the UK. ${ }^{5-7}$

Cancer in teenagers and young adults is uncommon - a GP may diagnose one such cancer in their working life. In the UK, approximately 2000 new cases of cancer are reported annually for teenagers and young adults; cancer is also the leading cause of non-accidental death for young people aged 15-24 years. ${ }^{8}$ Teenagers and young adults present with a spectrum of malignant diseases, the pattern of which is unique to this age group; leukaemia, lymphoma, cancers of the central nervous system, bone and soft tissue sarcomas, and germ-cell tumours predominate, accounting for almost three-quarters of new diagnoses. ${ }^{9}$

A prolonged period to cancer diagnosis in teenagers and young adults with cancer in the UK has been reported after retrospective examination of medical notes. ${ }^{10,11}$ In addition, unpublished analyses of characteristics of

LA Fern, PhD, MSc, research development coordinator, National Cancer Research Institute: Teenage \& Young Adult Clinical Studies Group University College Hospitals London NHS Foundation Trust, London. C Campbell, PhD, MSc public health senior research fellow; D Weller, PhD, MRCGP, MPH, head of general practice, General Practice Section, Centre for Population Health Sciences, The University of Edinburgh, Edinburgh. R Grant, MBChB, GP, Brycedale Surgery, Kirkcaldy, Fife. I Lewis, FRCP, paediatric oncologist; TOB Eden, FRCP, FRCP(Ed), emeritus professor of paediatric oncology, Academic Unit of Paediatric and Adolescent Oncology, University of Manchester, Manchester. U Macleod, PhD, FRCGP, FHEA, professor of primary care, Hull York Medical School, University of Hull, Hull. J Whelan, MD, FRCP, lead medical oncologist and teenagers and young adults with cancer entering a large European study of Ewing's sarcoma demonstrates that those registered in the UK have larger primary tumours and are more likely to have metastases than patients registered in France or Germany (I Lewis, personal communication, 2007). Young people with cancer self-report repeated visits to GPs prior to referral to an appropriate specialist and often describe multiple cancer symptoms. ${ }^{12,13}$ A qualitative study looking at the diagnostic experience of teenagers and young adults with cancer in the UK illustrates the complexity and prolonged period to cancer diagnosis for some young people. ${ }^{14} \mathrm{~A}$ further study also recognised the complexity of the diagnostic pathway and the difficulties faced by GPs when diagnosing teenagers and young adults with cancer. ${ }^{15}$

Referral from primary to secondary care is frequently triggered by an 'alert' symptom or symptoms, which may be suggestive of cancer. ${ }^{16}$ Policy documents now include these recognised symptoms and form the basis for referral guidelines for suspected cancer. ${ }^{17}$ The frequency of GP consultations involving potential alert symptoms that may be suggestive of cancer in the normal teenage and young adult population - such

academic teenage \& young adult cancer care lead, University College Hospitals NHS Foundation Trust, London.

\section{Address for correspondence}

Dr Jeremy Whelan, Department of Oncology,

University College Hospital, 1st Floor Central, 250 Euston Road, London NW1 2PG.

E-mail: jeremy.whelanduclh.nhs.uk

Submitted: 22 October 2010; Editor's response:

14 November 2010; final acceptance:

13 December 2010.

CBritish Journal of General Practice

This is the full-length article (published online 26 Apr 2011) of an abridged version published in print. Cite this article as: Br J Gen Pract 2011; DOI: 10.3399/bjgp11X572418. 


\section{How this fits in}

Improving the time to diagnosis of cancer has been set as a national priority and is particularly relevant to cancer occurring in teenagers and young adults. This study shows that young people attend their GP frequently but consultations involving 'alert' symptoms are rare $(4 \%)$. These data should inform future research directed towards the development of decision-aid tools and education programmes to improve the diagnosis of cancer in teenagers and young adults.

as unexplained pain, headache, lump or swelling, fatigue, and weight loss - have not previously been reported but, it would appear that, before cancer is diagnosed, cancer symptoms in teenagers and young adults with cancer are frequently attributed to common conditions such as sporting injuries, stress, and adolescent fatigue. ${ }^{12}$

Avoiding teenage pregnancy, dealing with drug use, and the provision of smokingcessation advice are frequently the focal point for adolescent primary care rather than ill health. There exists a common perception that teenagers and young adults are generally a healthy population who rarely present to their $\mathrm{GP},{ }^{18}$ but consultation patterns for younger teenagers aged 13-15years demonstrate that approximately $72.2 \%$ attend primary care at least once a year. ${ }^{19}$ There is relatively little published data on consultation patterns for older teenagers and young adults.

This study aimed to describe patterns of teenage and young adult presentation in three general practices in Scotland, and to gain a better understanding of how often alert symptoms that could be indicative of cancer were recorded.

\section{METHOD}

\section{Setting}

The three practices were located in the NHS board areas of Lothian, Greater Glasgow and Clyde, and Fife. One practice was situated within an inner-city area with a high proportion of patients with drug and mental health problems; one practice served both urban and rural areas, covering a wide socioeconomic spectrum; and the third was sited in an area of urban socioeconomic deprivation.

\section{Patients}

All face-to-face GP consultations over a 12month period 11 October 2006 to 29 September 2007) with teenagers and young adults were included. Home visits, telephone consultations, and practicenurse consultations were not included. Data fields included anonymised patient identification number, patient date of birth, date of consultation, sex, and free-text entries relating to the consultation.

\section{Data collection and coding}

Clinical details were extracted from computerised records and consultations coded into five categories:

- category A - consultations with no oncological significance;

- category B - consultations involving alert symptoms, such as an unexplained lump or swelling. All symptoms considered to have some potential oncological significance were included. Development of category-B criteria were based on the National Institute for Health and Clinical Excellence referral guidelines for children and young people with suspected cancer, ${ }^{20}$ and refined through an iterative process involving the GP as well as teenagers' and young adults' oncology research team. Any symptoms that could not be assigned to categories $A$ and $C$, or explained rationally, were also classed as Category B;

- category C - other clinical consultations including preventative advice;

- category D - did not involve any clinical condition, for example, return-to-work documentation; and

- category E - insufficient consultation details recorded.

Categories A and B were further divided, as outlined in Table 1. Coding was carried out by five researchers across the three practices; to ensure consistency in the approach taken, the research team met regularly to discuss any uncertainties.

\section{Statistical analysis}

To test for associations between categories, the $\chi^{2}$-test was used. If the P-value of $\chi^{2}$ is $\geq 0.05$, it can be assumed that the categories are independent. For P-values of $<0.05$, it can be assumed that there are 


\section{Table 1. Classification criteria for symptoms}

\begin{tabular}{|c|c|c|c|}
\hline Category & Description & Subcategory & Examples \\
\hline \multirow[t]{7}{*}{ A } & \multirow{7}{*}{$\begin{array}{l}\text { Presentations with no } \\
\text { oncological significance }\end{array}$} & A1 Skin complaint & Acne, eczema, dermatitis, psoriasis, excludes pigmented lesions \\
\hline & & $\begin{array}{l}\text { A2 Contraception or } \\
\text { pregnancy-related condition }\end{array}$ & $\begin{array}{l}\text { Contraceptive pill or injection, termination of pregnancy, } \\
\text { pre- and postnatal care }\end{array}$ \\
\hline & & $\begin{array}{l}\text { A3 Known chronic illness/review of } \\
\text { existing condition }\end{array}$ & Asthma, diabetes, cystic fibrosis \\
\hline & & A4 Simple infection & Respiratory tract infection, urinary tract infection \\
\hline & & A5 Mental health & Depression, anxiety \\
\hline & & A6 Multiple issues & $\begin{array}{l}\text { Numerous symptoms, none of which are category B; for example, } \\
\text { skin complaint, contraception, and mental health }\end{array}$ \\
\hline & & $\begin{array}{l}\text { A7 'Other' acute, clearly } \\
\text { non-oncological problem }\end{array}$ & $\begin{array}{l}\text { Trauma, eye problems, foreign bodies, dyspepsia, migraine, } \\
\text { haemorrhoids, diarrhoea, and vomiting; also includes first } \\
\text { presentation of headache, back pain and dizziness }\end{array}$ \\
\hline \multirow[t]{8}{*}{ B } & \multirow{8}{*}{$\begin{array}{l}\text { Presentations that could have } \\
\text { some oncological significance } \\
\text { (alert symptoms) }\end{array}$} & B1 lump/swelling & Breast, testis or other area \\
\hline & & B2 Lymphadenopathy & Swollen/enlarged lymph nodes \\
\hline & & B3 Headaches & $\begin{array}{l}\text { Persistent unexplained headaches, excludes migraine or headache } \\
\text { associated with viral illness }\end{array}$ \\
\hline & & B4 Fatigue & Persistent unexplained fatigue \\
\hline & & B5 Weight loss & Unexplained weight loss \\
\hline & & B6 Pain & Persistent unexplained pain \\
\hline & & B7 Dizziness & Unexplained dizziness \\
\hline & & B8 Other & $\begin{array}{l}\text { Examples include pigmented lesions, non-healing ulcers, rectal } \\
\text { bleeding, haematemesis, intermenstrual bleed }\end{array}$ \\
\hline $\bar{C}$ & $\begin{array}{l}\text { Other clinical conditions, } \\
\text { including preventative advice }\end{array}$ & $\mathrm{n} / \mathrm{a}$ & Smoking cessation, travel vaccine advice \\
\hline D & No clinical condition & $\mathrm{n} / \mathrm{a}$ & $\begin{array}{l}\text { Back-to-work papers, registering new patient, giving test results, } \\
\text { methadone prescriptions }\end{array}$ \\
\hline $\bar{E}$ & Inconclusive & $\mathrm{n} / \mathrm{a}$ & Insufficient details of consultation recorded \\
\hline
\end{tabular}

Figure 1. Consultation patterns of teenagers and young adults over 1 year, by age and sex.

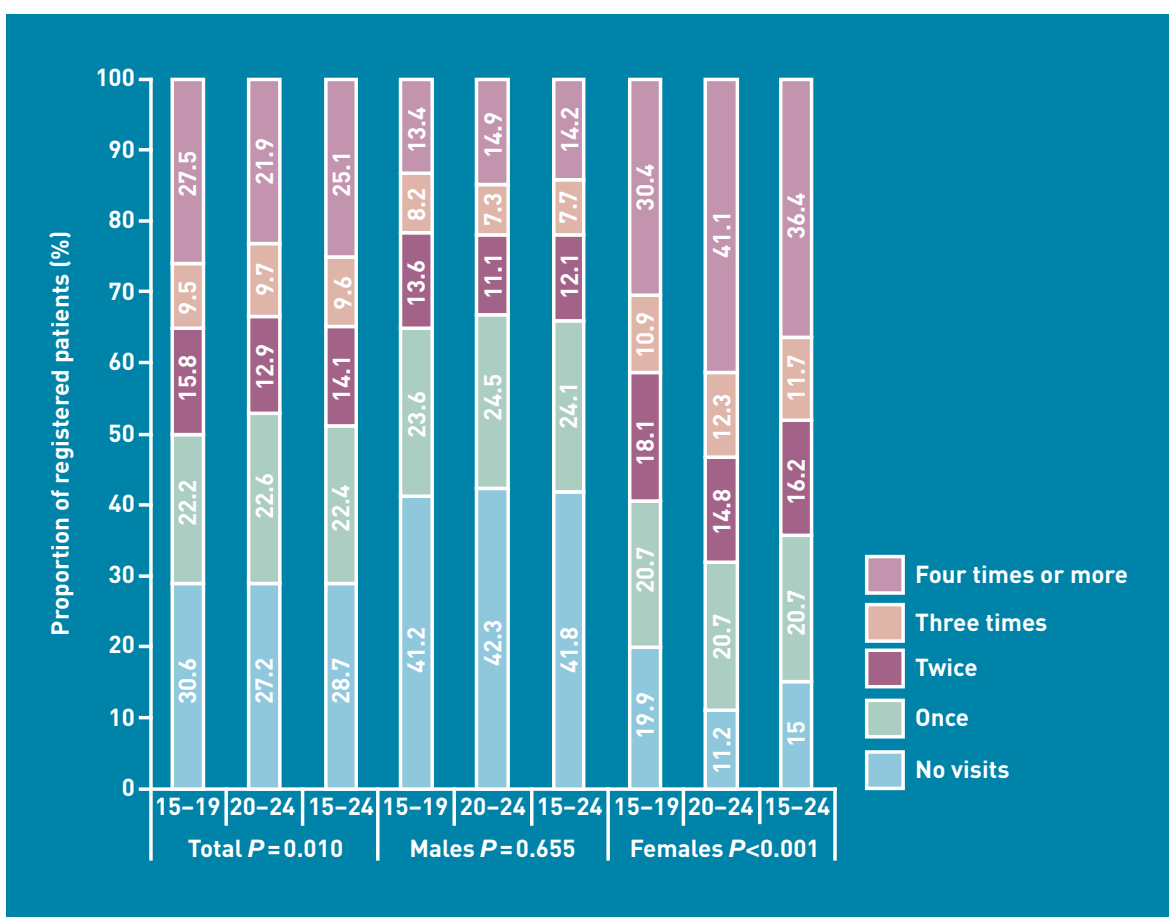

statistically significant differences between the distributions of categories at the $95 \%$ level.

\section{RESULTS}

The combined list size was 20068 , with $2326(11.6 \%)$ teenagers and young adults. The overall ratio of males to females was 1:0.96.

\section{Consultation frequency}

A total of 1659 discrete patients consulted at least once during the year, representing $71.3 \%$ of registered teenagers and young adults. Figure 1 shows the proportion of patients consulting, by age and sex, including those who did not consult. During the reporting period, $22.4 \%$ consulted once, $14.1 \%$ consulted twice, $9.6 \%$ consulted three times, and over a quarter (25.1\%) consulted four times or more. A total of 6377 consultations with teenagers and young adults were recorded, the mean consultation rate (CR) for all registered teenagers and young adults being 2.7 consultations per year. Consultation frequency was higher for young adults: the CR for those aged 15-19 years was 2.2 compared with 3.1 for those aged 20-24 years $(P=0.0104)$.

Females had significantly higher CRs 
Table 2. Number of consultations by sex, age, and reason, with breakdown of category-A consultations

\begin{tabular}{|c|c|c|c|c|c|c|c|c|c|}
\hline \multirow[b]{2}{*}{ Reason for consultation } & \multicolumn{3}{|c|}{$15-19$ years } & \multicolumn{3}{|c|}{$20-24$ years } & \multicolumn{3}{|c|}{$15-24$ years combined } \\
\hline & Male $\mathrm{n}(\%)$ & Female $\mathrm{n}(\%)$ & All n (\%) & Male $\mathrm{n}(\%)$ & Female $\mathrm{n}(\%)$ & All n (\%) & Male $\mathrm{n}(\%)$ & Female $\mathrm{n}(\%)$ & All n (\%) \\
\hline $\begin{array}{l}\text { Category A: no oncological } \\
\text { significance (total) }\end{array}$ & $606(75.7)$ & $1234(84.4)$ & 1840 (81.3) & 910 (70.7) & 2251 (79.7) & $3161(76.8)$ & $1516(72.6)$ & 3485 (81.3) & $5001(78.4)$ \\
\hline $\begin{array}{l}\text { Contraception or } \\
\text { pregnancy related }\end{array}$ & 4 (0.7ㄹ) & 305 (24.7ㄹ) & 309 (16.8) & 3 (0.3a) & 695 (30.9a) & 698 (22.19) & $7\left(0.5^{\mathrm{a}}\right)$ & 1000 (28.7ㄹ) & 1007 (20.1) \\
\hline $\begin{array}{l}\text { Known chronic illness/ } \\
\text { review of existing condition }\end{array}$ & $70\left(11.6^{a}\right)$ & $82\left(6.6^{a}\right)$ & 152 (8.3) & 135 (14.9a) & $171\left(7.6^{a}\right)$ & 306 (9.7) & 205 (13.5) & 253 (7.3) & $458\left(9.2^{\mathrm{a}}\right)$ \\
\hline Simple infection & $179\left(29.5^{a}\right)$ & 270 (21.9a) & $449\left(24.4^{\mathrm{a}}\right)$ & $173\left(19.0^{a}\right)$ & 381 (16.9a) & $554\left(17.5^{\text {a) }}\right.$ & $352\left(23.2^{\mathrm{a}}\right)$ & 651 (18.7ㄹ) & 1003 (20.0 $)$ \\
\hline Mental health & $57\left(9.4^{\mathrm{a}}\right)$ & 93 (7.5a) & $150\left(8.2^{\mathrm{a}}\right)$ & 202 (22.2a) & 389 (17.3) & 591 (18.7) & 259 (17.19) & $482\left(13.8^{a}\right)$ & $741\left(14.8^{a}\right)$ \\
\hline Multiple issues & $28\left(4.6^{\mathrm{a}}\right)$ & 144 (11.7ㅇ) & $172\left(9.3^{\text {a) }}\right.$ & $60\left(6.6^{\mathrm{a}}\right)$ & $221\left(9.8^{a}\right)$ & 281 (8.9a) & 88 (5.8) & $365\left(10.5^{a}\right)$ & $453\left(9.1^{\text {a) }}\right.$ \\
\hline Acute non-oncological & 135 (22.3) & $197\left(16.0^{a}\right)$ & 332 (18.0) & $226\left(24.8^{a}\right)$ & $253\left(11.2^{\mathrm{a}}\right)$ & 479 (15.19) & $361\left(23.8^{a}\right)$ & 450 (12.9a) & $811\left(16.2^{\mathrm{a}}\right)$ \\
\hline $\begin{array}{l}\text { Category B: may have some } \\
\text { oncological significance }\end{array}$ & 46 (5.7) & $59(4.0)$ & $105(4.6)$ & 50 (3.9) & 100 (3.5) & $150(3.6)$ & $96(4.6)$ & 159 93.71 & $255(4.0)$ \\
\hline $\begin{array}{l}\text { Category C: other } \\
\text { clinical conditions }\end{array}$ & $37(4.6)$ & 33 (2.3) & $70(3.1)$ & $56(4.3)$ & $171(6.1)$ & $227(5.5)$ & $93(4.5)$ & $204(4.8)$ & 297 (4.7) \\
\hline $\begin{array}{l}\text { Category E: insufficient } \\
\text { record of consultation }\end{array}$ & $1(0.1)$ & $2(0.1)$ & $3(0.1)$ & $2(0.2)$ & $2(0.1)$ & $4(0.1)$ & $3(0.1)$ & $4(0.1)$ & $7(0.1)$ \\
\hline Total & 801 & 1462 & 2263 & 1288 & 2826 & 4114 & 2089 & 4288 & 6377 \\
\hline
\end{tabular}

than males: $85 \%$ of females aged 1524 years consulted once, compared with $58.2 \%$ of males (CR: 3.8 versus 1.9. $P<0.0001)$. This was consistent across both age groups (Figure 1). Older females were more likely to consult than younger females (CR: 4.4 versus $2.9, P<0.0001$ ), but there was little difference in consultation frequency for males aged 15-19 years and those aged 20 24 years (CR: 1.6 versus $1.9, P=0.655$ ].

\section{Reasons for consultation}

Table 2 summarises the reasons for consultation, by age and sex, and provides a breakdown of category A consultations. These were most frequently reported. accounting for $78.4 \%$ of all consultations, followed by those classified as category $D$, (no clinical condition, $12.8 \%$ ) and category $\mathrm{C}$ (other clinical conditions, 4.7\%). Category B lalert symptoms) accounted for $4.0 \%$ of consultations. Seven consultations $(0.1 \%)$ had insufficient or no clinical details recorded.

\section{Consultations in Category $\mathrm{A}$}

As highlighted in Table 2, overall, the most frequent consultations classified as category A were for contraception/pregnancy and infection (both 20.1\%). The most frequent reason for consultation for 15-19 year olds was infection (24.4\%), followed by acute miscellaneous consultations (18.0\%). The most frequent reason for consultation for those aged 20-24years was contraception/pregnancy (22.1\%), followed by consultations related to mental health problems (18.7\%).

\section{Consultation patterns by age and sex}

Reasons for consultation differed by age (Table 2). The frequency of skin complaints fell in the older age group, while the proportion of mental health consultations in those aged 20-24 years was more than twice as high as those aged 15-19 years. Consultations involving multiple symptoms, none of which were alert symptoms, accounted for $9.1 \%$ of consultations; this did not differ greatly by age, but females were more likely to report with multiple issues than males. Nearly a third (28.7\%) of females attended for contraception/pregnancy advice. Among males the most frequent reason for consultation was for acute miscellaneous symptoms (23.8\%), followed by infection (23.2\%).

\section{Alert symptoms}

A total of 255 consultations were considered to involve an alert symptom and accounted for $4.0 \%$ of all consultations (Table 2). These symptoms were recorded in 179 patients $17.7 \%$ of registered teenagers and young 


\section{Table 3. Distribution and mean of alert symptoms by sex and age}

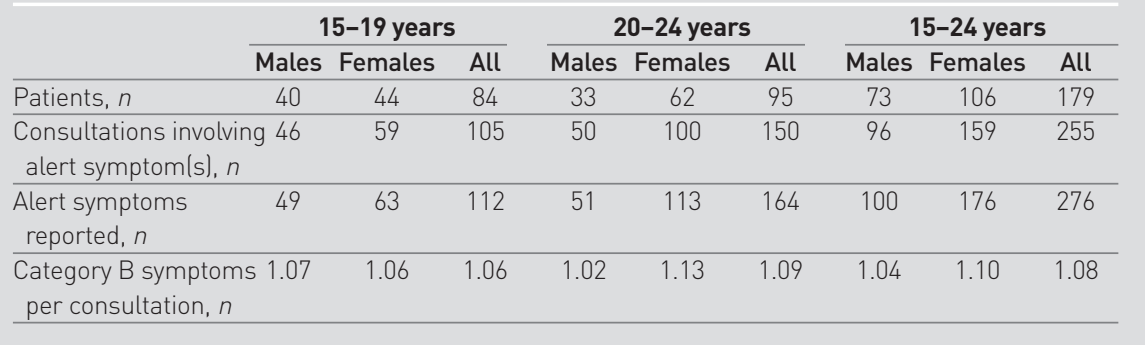

adults) and their proportion did not vary significantly by age or sex. For both age groups, males had a slightly higher proportion of consultations involving alert symptoms than females: $5.7 \%$ for males aged $15-19$ years $(n=46)$ compared with $4.0 \%$ for females aged $15-19$ years $(n=59)$. For patients aged 20-24 years, the difference between male and female was less $(3.9 \%$ versus $3.5 \%$ respectively).

The mean number of alert symptoms reported per consultation involving such symptoms was 1.08 , ranging from 1.02 for males aged $20-24$ years to 1.13 for females aged $20-24$ years. A total of 276 potential oncological symptoms were recorded (Table 3). The most frequently reported specific alert symptoms were unexplained pain (34.8\%, $n=96)$, fatigue $(14.5 \%, n=40)$, lumps $(13.4 \%, n=37)$, and headache $(8.0 \%$, $n=22$ ) (Table 4). This was consistent across all age groups and sex with the exclusion of females aged 15-19 years whose fourth most frequently reported potential oncological symptom was lymphadenopathy, accounting for $6.3 \%(n=$ 4) and pigmented lesion, also $6.3 \%(n=4)$
For males aged 20-24 years the fourth most frequently reported 'alert' symptom was pigmented lesion, $7.8 \%(n=4)$, and for males aged 15-19 years, rectal bleeding was the fourth most common alert symptom, $8.2 \%(n=4)$. Table 4 shows the 10 most common alert symptoms, by age and sex, that accounted for $87.3 \%$ of all reported alert symptoms over the 12-month period.

Lumps were most frequently located in the breast and testis, accounting for half of all lumps (54.1\%, $n=20)$; of those, 12 $(32.4 \%)$ were in the breast and included four male patients (data not shown). One case of female nipple inversion was documented. Testicular lumps accounted for $21.6 \%$ of lumps; a further four symptoms related to the testis were recorded - two of pain, and two of swelling. The remainder of the lumps was distributed through various anatomical sites including the jaw, groin, neck, and chest.

Most alert symptoms were reported in isolation but fatigue was most likely to be reported along with other symptoms, including weight loss, nausea, and dizziness.

\section{Table 4. Distribution of alert symptoms by sex and age}

\begin{tabular}{|c|c|c|c|c|c|c|c|c|c|}
\hline \multirow[b]{2}{*}{ Alert symptom, $n$} & \multicolumn{3}{|c|}{ Males, $n(\%)$} & \multicolumn{3}{|c|}{ Females, $n(\%)$} & \multicolumn{3}{|c|}{ Total, $n(\%)$} \\
\hline & $15-19$ years & $20-24$ years & $15-24$ years & $15-19$ years & $20-24$ years & $15-24$ years & $15-19$ years & $20-24$ years & $15-24$ years \\
\hline Pain (all) & 16 (32.7) & $22(43.1)$ & 38 (38.0) & $20(31.7)$ & 38 (33.6) & 58 (33.0) & $36(32.1)$ & $60(36.6)$ & 96 (34.8) \\
\hline Fatigue/tiredness & $6(12.2)$ & $2(3.9)$ & $8(8.0)$ & $8(12.7)$ & $24(21.2)$ & $32(18.2)$ & 14 (12.5) & $26(15.9)$ & $40(14.5)$ \\
\hline Lumps (all) & $11(22.4)$ & $7(13.7)$ & $18(18.0)$ & $9(14.3)$ & $10(8.8)$ & $19(10.8)$ & 20 (17.9) & $17(10.4)$ & 37 (13.4) \\
\hline Headache & $4(8.2)$ & $6(11.8)$ & $10(10.0)$ & $3(4.8)$ & $9(8.0)$ & $12(6.8)$ & $7(6.3)$ & $15(9.1)$ & $22(8.0)$ \\
\hline Rectal bleeding & $4(8.2)$ & $2(3.9)$ & $6(6.0)$ & $1(1.6)$ & $7(6.2)$ & $8(4.5)$ & $5(4.5)$ & $9(5.5)$ & $14(5.1)$ \\
\hline Pigmented lesion & $0(0.0)$ & $4(7.8)$ & $4(4.0)$ & $4(6.3)$ & $1(0.9)$ & $5(2.8)$ & $4(3.6)$ & $5(3.0)$ & 9 (3.3) \\
\hline Lymphadenopathy & $0(0.0)$ & $1(2.0)$ & $1(1.0)$ & $4(6.3)$ & $2(1.8)$ & 6 (3.4) & $4(3.6)$ & $3(1.8)$ & 7 (2.5) \\
\hline Weight loss & $2(4.1)$ & $0(0.0)$ & $2(2.0)$ & $3(4.8)$ & $1(0.9)$ & $4(2.3)$ & $5(4.5)$ & $1(0.6)$ & $6(2.2)$ \\
\hline Fainting & $0(0.0)$ & $0(0.0)$ & $0(0.0)$ & $0(0.0)$ & $5(4.4)$ & 5 (2.8) & $0(0.0)$ & 5 (3.0) & $5(1.8)$ \\
\hline Post-coital bleed & $0(0.0)$ & $0(0.0)$ & $0(0.0)$ & 2 (3.2) & $3(2.7)$ & $5(2.8)$ & $2(1.8)$ & $3(1.8)$ & $5(1.8)$ \\
\hline Other & 6 (12.2) & $7(13.7)$ & $13(13.0)$ & $9(14.3)$ & 13 (11.5) & 22 (12.5) & 15 (13.4) & 20 (12.2) & 35 (12.7) \\
\hline Total & $49(100.0)$ & $51(100.0)$ & $100(100.0)$ & $63(100.0)$ & $113(100.0)$ & $176(100.0)$ & $112(100.0)$ & $164(100.0)$ & 276 (100.0) \\
\hline
\end{tabular}




\section{Tumour diagnoses during the period of the study}

Two benign tumours occurred, one nonfunctioning anterior pituitary adenoma and a benign skin tumour. In addition, one case of severe cervical dyskaryosis was reported in a 24-year-old female; the patient was immediately referred for colposcopy.

\section{DISCUSSION}

\section{Summary of main findings}

The study has shown that approximately $70 \%$ of teenagers and young adults registered at their GP at least once during a 1 -year period. As this study did not include nurse consultations, home visits, or telephone consultations, the proportion of teenagers and young adults who interacted with primary care services is likely to be higher. Consultation frequency was associated with age and sex - those aged 20-24 years were more likely to attend than those aged 15-19 years; of the cohort, females aged $20-24$ years were least likely to consult a GP and males aged $15-19$ years were least likely to consult a GP. There was no consistent association between increasing age and consultation patterns for males. Contraception/pregnancy, infection, and mental health issues were the most common specific reasons for consultations among teenagers and young adults.

Although the most frequent reason for consultation across the three practices in this study did vary (reflecting demographic differences), the frequency of potential cancer symptoms was similar across all three practices, and by age and sex. A total of $255(4.0 \%)$ consultations reported potential cancer symptoms, which were most likely to be reported in isolation - an important finding given that approximately $60 \%$ of young people attending their GP prior to cancer diagnosis report having three or more symptoms. ${ }^{11}$

\section{Strengths and limitations of the study}

One of the strengths of the study is that it did not rely on Read Codes alone as the basis of coding the reasons for consultation into each category, but also used the free-text entries; this process of using both is complex and expensive and rarely achieved in large studies using GP databases. However, as in any other study using GP data, the study acknowledges that these data were collected for clinical, not study, purposes; as such they may under-reflect the true rate of presentation if, for example, in a consultation whose primary purpose is for contraception, the GP is also, almost as an aside, asked to comment on a mole. Many GPs will record both of these land there were such examples in the data set), but it is possible that in some cases only the main reason for the consultation is recorded.

Alert symptoms were based on guidance from the UK's Department of Health and consensus between study investigators. There is a limited evidence base informing these processes; research examining positive predictive values of symptoms as they present in primary care for cancers is at a relatively early stage.

\section{Comparison with existing literature}

Although uncommon in young people, cancer is the leading disease-related cause of death for those aged 15-24 years. ${ }^{21,22}$ Young people themselves emphasise the importance of timely diagnosis, with $60 \%$ of teenagers and young adults with cancer at a recent patient conference identifying the improvement of time to cancer diagnosis as the most important area of research..$^{23}$ Understanding how and why young people use primary care services is an important step in developing education tools and strategies that could help GPs to identify and refer appropriately young people with a suspected cancer sooner than they do at present.

\section{Implications for research}

This study highlights the very significant challenges GPs face in promptly recognising the possibility of cancers in teenagers and young people when they present with potential oncological symptoms. These cancers are rare - a GP may diagnose one such cancer in his or her working life; however, much of the potential for reducing time to diagnosis does reside in primary care and this study represents an important step in producing evidence to enhance the process of optimal recognition and referral. This study has demonstrated that, contrary to common perception, teenagers and young adults do consult their GP sufficiently often to provide opportunities for improved early cancer diagnosis.

The process of cancer diagnosis in primary care is complex - experience to this article on the Discussion Forum:

http://www.rcgp.org.uk/bjgp-discuss 
date suggests that it is relatively uncommon to make a diagnosis of cancer, or even make a referral for suspected cancer, on a single primary care visit. ${ }^{24}$ Rather, the diagnosis may emerge after more than one visit, in which signs and symptoms are observed over a period of time, and information from investigations and other sources is obtained. A substantive body of research highlights the unique biological, cognitive, and psychosocial characteristics of teenagers and young adults who moderate their use of primary care services; ${ }^{25}$ as a result of this moderation, it is a particular challenge for primary care providers to capitalise on opportunities for diagnosis in this population.

The study developed a coding strategy to classify consultations according to whether or not they have potential oncological significance. An analysis of cancer diagnoses in young people in primary care in 2009 highlighted the complexity of the process. ${ }^{15}$ This, coupled with the reported lack of satisfaction by teenagers with their contacts within primary care, ${ }^{26-30}$ suggests that further research and education in this field should be prioritised. ${ }^{24}$
Although progress is being made in identifying alert symptoms - particularly for common cancers such as lung and colorectal cancer ${ }^{16,31}$ - such work is much more challenging for rare cancers, such as those occurring in teenagers and young adults. Further research is required to provide evidence relating to symptoms and cluster symptoms prior to cancer diagnosis in teenagers and young adults. In addition, further work is required in a larger cohort of patients to validate this strategy of detecting 'alert' symptoms in teenagers and young adults that warrant prompt, targeted investigation or referral and earlier diagnosis. A study involving many practices with longer follow up may determine the positive predictive value of this coding system, and perhaps reveal other unidentified alert symptoms or symptom complexes for young people with cancer. This would be further aided by more detailed investigations of patterns of primary care consultations for young people who have been diagnosed with cancer. This study adds further evidence to the need for symptombased research in primary care to inform cancer-referral guidelines. ${ }^{24}$ 


\section{REFERENCES}

1. Department of Health. Cancer reform strategy, achieving local implementation - second annual report. London: Department of Health, 2009. http://www.dh.gov.uk/prod_consum_dh/groups/dh_digitalassets/ documents/digitalasset/dh_109597.pdf (accessed 17 Mar 2011)

2. Department of Health. Cancer reform strategy. London: Department of Health, 2007. http://www.dh.gov.uk/prod_consum_dh/groups/ dh_digitalassets/documents/digitalasset/dh_081007.pdf laccessed 17 Mar 2011)

3. Richards MA. The national awareness and early diagnosis Initiative in England: assembling the evidence. Br J Cancer 2009;101 Suppl 2 :S1-4

4. National Institute for Health and Clinical Excellence. Improving outcomes in children and young people with cancer. NICE: London, 2005. http://www.nice.org.uk/nicemedia/live/10899/28876/28876.pdf laccessed 17 Mar 2011)

5. Sant M, Allemani C, Santaquilani M, et al. EUROCARE-4. Survival of cancer patients diagnosed in 1995-1999. Results and commentary. Eur J Cancer 2009; 45(6): 931-991.

6. Andersen BL, Cacioppo JT. Delay in seeking a cancer diagnosis: delay stages and psychophysiological comparison processes. Br J Soc Psychol 1995; 34(Pt 1): 33-52.

7. Andersen RS, Vedsted P, Olesen F, et al. Patient delay in cancer studies: a discussion of methods and measures. BMC Health Serv Res 2009; 9: 189.

8. Geraci M, Birch JM, Alston RD, et al. Cancer mortality in 13 to 29-year-olds in England and Wales, 1981-2005. Br J Cancer 2007; 97(11): 1588-1594.

9. Alston AD, Geraci M, Eden TOB, et al. Changes in Cancer incidence in teenagers and young adults (Ages 13 to 24 years) in England 1979-2003. Cancer 2008; 113(10): 2807-2815.

10. Goyal S, Roscoe J, Ryder WD, et al. Symptom interval in young people with bone cancer. Eur J Cancer 2004; 40(15): 2280-2286.

11. Eden $T$, Rogers $M$, Barker $L$, et al. Symptom interval in teenagers and young adults with cancer. Ped Blood Cancer 2007; 49, (4): 575 (abstr PS 016).

12. Smith $S$, Davies $S$, Wright $D$, et al. The experiences of teenagers and young adults with cancer - results of 2004 conference survey. Eur J Oncol Nurs 2007; 11(4): 362-368.

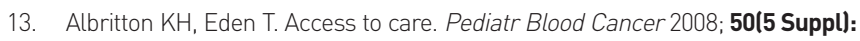
1094-1098.

14. Pearce SGF, Eden T, Glaser L, et al. The experiences of young people from first symptoms to the diagnosis of cancer: a narrative study. Eur J Cancer 2009; 7(2): 234.

15. Mitchell ED. MU, Rubin GP. Cancer in primary care: an analysis of significant event audits for cancer diagnosis, 2008-2009. Final report to the National Awareness and Early Diagnosis Initiative. 2009.

http://www.rcgp.org.uk/pdf/CIRC_Analysis\%20of\%20SEA\%20for\%20cancer\%2 Odiagnosis\%20final\%20report.pdf laccessed 8 Apr 2011).

16. Jones R, Latinovic R, Charlton J, Gulliford MC. Alarm symptoms in early diagnosis of cancer in primary care: cohort study using General Practice Research Database. BMJ 2007; 334(7602): 1040.

17. Department of Health. Referral guidelines for suspected cancer. London: Department of Health, 2000. http://www.dh.gov.uk/prod_consum_dh/ groups/dh_digitalassets/dadh/den/documents/digitalasset/dh_4014421.pdf laccessed 17 Mar 2011)

18. McPherson A. Adolescents in primary care. BMJ 2005; 330(7489): 465-467.

19. Churchill R, Allen J, Denman S, et al. Do the attitudes and beliefs of young teenagers towards general practice influence actual consultation behaviour? Br J Gen Pract 2000; 50(461): 953-957.

20. National Institute for Health and Clinical Excellence. Referral guidelines for suspected cancer. London: NICE, 2005.

http://www.nice.org.uk/nicemedia/pdf/cg027niceguideline.pdf laccessed 17 Mar 2011)

21. Birch JM, Pang D, Alston RD, et al. Survival from cancer in teenagers and young adults in England. Br J Cancer 2008; 99(5): 830-835.

22. Fern L, Davies S, Eden T, et al. Rates of inclusion of teenagers and young adults in England into National Cancer Research Network clinical trials: report from the National Cancer Research Institute (NCRI) Teenage and Young Adult Clinical Studies Development Group. Br J Cancer 2008; 99(12): 1967-1974.

23. Fern L, Ashton J, Brooman K, et al. Involving young people with cancer in research The National Cancer Research Institutes Teenage and Young Adult (TYA) Core Consumer Group (CCG) - a new and evolving model. Birmingham: National Cancer Research Institute, 2009. http://www.ncri.org.uk/ncriconference/2009abstracts/abstracts/C3.htm laccessed 17 Mar 2011)

24. Hamilton W. Cancer diagnosis in primary care. Br J Gen Pract 2010; 60(571): $121-128$.

25. Tylee A, Haller DM, Graham T, et al. Youth-friendly primary care services: how are we doing and what more needs to be done? Lancet 2007; 369(9572): 1565-1573.

26. Jacobson L, Kinnersley P. Teenagers in primary care - continuing the new direction. Br J Gen Pract 2000; 50(461): 947-948.

27. McPherson A, Macfarlane A, Allen J. What do young people want from their GP? Br J Gen Pract 1996; 46(411): 627.

28. Jacobson L, Richardson G, Parry-Langdon N, Donovan C. How do teenagers and primary healthcare providers view each other? An overview of key themes. Br J Gen Pract 2001; 51(471): 811-816.

29. Kari J, Donovan C, Li J, Taylor B. Adolescents' attitudes to general practice in north London. Br J Gen Pract 1997; 47(415): 109-110.

30. Donovan C, Mellanby AR, Jacobson LD, et al. Teenagers' views on the general practice consultation and provision of contraception. The Adolescent Working Group. Br J Gen Pract 1997; 47(424): 715-718.

31. Hamilton W, Round A, Sharp D, Peters TJ. Clinical features of colorectal cancer before diagnosis: a population-based case-control study. $\mathrm{Br} J$ Cancer 2005; 93(4): 399-405. 